Editor's Note: These short reviews of a recent paper in the Journal, written exclusively by graduate students or postdoctoral fellows, are intended to mimic the journal clubs that exist in your own departments or institutions. For more information on the format and purpose of the Journal Club, please see http://www.jneurosci.org/misc/ifa_features.shtml.

\title{
Proliferating Neural Precursor Cells as First Step toward Neuroregeneration in Huntington's Disease?
}

\author{
Mannie M. Y. Fan and Jing Fan \\ Graduate Program of Neuroscience, University of British Columbia, Vancouver, British Columbia, Canada V6T 1Z3 \\ Review of Batista et al. (http://www.jneurosci.org/cgi/content/full/26/41/10452)
}

Endogenous neural stem cells (NSCs) within the adult mammalian forebrain have been demonstrated to undergo enhanced cell proliferation and differentiation in response to neurodegenerative disease. Increased proliferation of cells in the subependyma (SE) was also noted in the human Huntington's disease (HD) brain. A recent article in The Journal of Neuroscience (Batista et al., 2006) demonstrated non-cell-autonomous-induced increase in NSC numbers along with altered migration of neural progenitors into the striatum in the R6/2 mouse model of HD.

To measure the number of NSCs in vivo, the authors used the in vitro neurosphere assay and determined that the total number of spheres forming from cells isolated from the SE was progressively increased in symptomatic R6/2 animals relative to wild-type (wt), in an age-dependent manner [Batista et al. (2006), their Fig. $1 A, B$ (http://www.jneurosci.org/cgi/content/full/ 26/41/10452/F1)]. Examining retention of bromodeoxyuridine (BrdU) labeling over $30 \mathrm{~d}$ confirmed the specific increase of NSC numbers in symptomatic R6/2 mice. Additional support for BrdU+ cells in the SE as being NSCs came from the observation that the vast majority of these cells expressed both nestin and GFAP, reflecting the multi-

Received Nov. 7, 2006; revised Nov. 15, 2006; accepted Nov. 16, 2006 Correspondence should be addressed to either Mannie M. Y. Fan or Jing Fan, Graduate Program of Neuroscience, University of British Columbia, Vancouver, British Columbia, Canada V6T 1Z3. E-mail: fj@interchange.ubc.ca or manniefa@interchange.ubc.ca.

DOI:10.1523/JNEUROSCI.4832-06.2006

Copyright $\odot 2006$ Society for Neuroscience $\quad$ 0270-6474/06/2613411-02\$15.00/0 potent nature of NSCs [Batista et al. (2006), their Fig. 2 (http://www.jneurosci.org/cgi/ content/full/26/41/10452/F2)]. Morphological analysis of cells in the SE by electron microscopy also demonstrated a specific increase in the proportion of type B cells, which correspond to putative stem cells, in $\mathrm{R} 6 / 2$ animals relative to controls [Batista et al. (2006), their Fig. 3A-G (http:// www.jneurosci.org/cgi/content/full/26/41/ 10452/F3)].

Self-renewal capacity of NSCs from symptomatic R6/2 mice was also increased [Batista et al. (2006), their Fig. $4 \mathrm{~A}$ (http://www.jneurosci.org/cgi/content/ full/26/41/10452/F4)]. Interestingly, cells cultured from presymptomatic R6/2 mice gave rise to similar numbers of neurospheres formed as did wt mice, and did not display increased expansion capacity [Batista et al. (2006), their Fig. $4 B$ (http:// www.jneurosci.org/cgi/content/full/26/ $41 / 10452 / F 4)]$, indicating that potentiation of the self-renewal ability of subependymal NSCs from symptomatic R6/2 mice may be induced by factors in the intact brain during symptom onset. Despite increased clonal expansion, the multipotentiality of NSCs is not different between R6/2 and wt, because comparable proportions of neurons, astrocytes, and oligodendrocytes are formed from NSCs of either genotype. Furthermore, the authors found no significant difference in the proliferation of subependymal progenitors from $\mathrm{R} 6 / 2$ mice relative to wt, using either cumulative BrdU labeling or immunolabeling for PCNA (proliferating cellular nucleus anti- gen) and BrdU [Batista et al. (2006), their Fig. 5A-D (http://www.jneurosci.org/cgi/ content/full/26/41/10452/F5)].

Importantly, 13-week-old R6/2 mice exhibited significantly lower densities of BrdU+ neural precursor cells in the olfactory bulb, whereas BrdU-labeled cells were more abundant in the R6/2 striatum relative to $\mathrm{wt}$, suggesting a redirection of precursor cells into the striatum in R6/2 mice [Batista et al. (2006), their Fig. 6A, B (http://www.jneurosci.org/cgi/content/ full/26/41/10452/F6) and Fig. 7A-C (http://www.jneurosci.org/cgi/content/ full/26/41/10452/F7)]. No significant difference was found between wt and R6/2 mice in terms of numbers of BrdU + cells that labeled for NeuN, nestin, or GFAP [Batista et al. (2006), their Fig. 8 (http:// www.jneurosci.org/cgi/content/full/26/ 41/10452/F8)].

Apart from two controversial reports of reduced or unchanged neurogenesis in R6/2 mice (Phillips et al., 2005, 2006) and a study showing increased neural precursor cell proliferation in a quinolinic acid (QA) lesion model of HD (Tattersfield et al., 2004), this may be the first study providing an elegant demonstration of an acquired, heritable potentiation of clonal expansion of subependymal NSCs and their recruitment to the striatum in the R6/2 mouse model of HD once disease is manifest, in agreement with previous findings from human HD patients (summarized in Table 1). At 4.5 weeks of age, a time shortly after onset of disease symptoms, proliferation of subependymal stem 
Table 1. Summary of altered neurogenesis and/or migration of neural precursors in HD patients and rodent models

\begin{tabular}{|c|c|c|c|c|c|}
\hline Reference(s) & Model & Brain region examined & Neurogenesis & Cell proliferation & Migration of neuronal precursors \\
\hline Curtis et al., 2003, 2005 & HD patient & Subependymal layer & Increased & Increased & $\mathrm{N} / \mathrm{A}$ \\
\hline Tattersfield et al., 2004 & QA lesion in rat & Subventricular zone & Increased & Increased & Into striatum \\
\hline \multirow[t]{2}{*}{ Gil et al., 2005} & \multirow[t]{2}{*}{$\mathrm{R} 6 / 2$ mouse } & Dentate gyrus & Reduced & Reduced & \multirow[t]{2}{*}{ N/A } \\
\hline & & Subventricular zone & N/A & No change & \\
\hline \multirow[t]{2}{*}{ Phillips et al., 2005} & \multirow[t]{2}{*}{ R6/2 mouse } & Dentate gyrus & $\begin{array}{l}\text { No change in response } \\
\text { to seizures }\end{array}$ & Reduced & \multirow[t]{2}{*}{$\mathrm{N} / \mathrm{A}$} \\
\hline & & Subventricular zone & No change & $\mathrm{N} / \mathrm{A}$ & \\
\hline \multirow[t]{2}{*}{ Phillips et al., 2006} & \multirow[t]{2}{*}{ R6/2 mouse } & Piriform and insular cortex & Reduced & $\mathrm{N} / \mathrm{A}$ & \multirow[t]{2}{*}{$\mathrm{N} / \mathrm{A}$} \\
\hline & & $\begin{array}{l}\text { Temporal germinal layer or } \\
\text { caudal subventricular zone }\end{array}$ & No change & $N / A$ & \\
\hline Lazic et al., 2004, 2006 & R6/1 mouse & Dentate gyrus & Reduced & Reduced & Into granular cell layer \\
\hline
\end{tabular}

N/A, Nonapplicable, not examined.

cells is not yet increased, indicating that symptom onset precedes the increase in self-renewal capacity of these NSCs. Once induced by factors accompanying disease onset, the augmented capacity for clonal expansion appears to be heritable and is maintained from one cell generation to the next during in vitro serial passaging of neurosphere colonies. Thus, it is likely that these induction factors involve epigenetic changes, in which heritable transcriptional gene unsilencing (or silencing) may take place through changes in histone modification and/or DNA methylation to switch on activators (or switch off repressors) of pathways leading to enhanced self-renewal of these NSCs. Importantly, these factors are specific not only to the expression of mhtt in R6/2 mice, but are induced only after disease symptoms become manifest, suggesting that development of this modified phenotype is dependent on factor(s) associated with symptom onset. Hence, changes in the environment surrounding subependymal NSCs during symptom onset somehow triggers epigenetic changes to produce the heritable phenotype; whether these changes contribute to disease progression is far from certain.

Despite an increase in the number of NSCs, it is unclear whether these surviving new "neurons" form functional synaptic connections within the preexisting neuronal circuitry. The fact that symptoms continue to progressively worsen in both human HD patients and the R6/2 mice argues against any significant functional rescue by these new precursor cells. In a QA lesion model of HD in rat, neural progenitors transplanted into the striatum not only survived and differentiated, but most importantly were able to reduce motor impairments (Vazey et al., 2006). Thus, the normal progression of disease we observe in R6/2 mice may already be the improved outcome and ameliorated phenotype resulting from redirection of the expanded NSC population into the striatum. If this is indeed the case, factors that can fur- ther promote an increase in NSC numbers, migration into the striatum, and/or proper differentiation and survival may prove to be useful in the treatment of HD.

Previous studies showed that BDNF overexpression led to increased numbers of new neurons in both the olfactory bulb and striatum (Benraiss et al., 2001), and yet migration to the olfactory bulb is decreased, whereas targeting of precursor cells to the striatum is increased in $\mathrm{R} 6 / 2$ mice that express reduced levels of BDNF (Zuccato et al., 2005). Are there additional factors that override the BDNF signal to cause selective redirection of precursor cells into the striatum? Moreover, is the increase in self-renewal capacity of the neural precursor cells related to the altered migratory path of these cells? Do these two phenomena act in an attempt to protect against mhtt toxicity, or could they contribute to the toxicity by pathogenically altering neuronal numbers and/or migration, or are they inconsequential, arising as a mere side effect of mhtt expression? What are the epigenetic changes that are responsible for the generation of these phenomena? Is it possible to manipulate the heritable changes in gene function so as to alter NSC self-renewal capacity and/or migratory path? These are some of the questions that remain to be determined. Future challenges will include the identification of signals and mediators of the epigenetic changes leading to increased NSC expansion, as well as factor(s) that may be induced to facilitate the incorporation of these precursor cells into the neuronal network to improve functional outcome even after disease symptoms become manifest.

\section{References}

Batista CMC, Kippin TE, Willaime-Morawek S, Kimie Shimabukuro M, Akamatsu W, van der Kooy D (2006) A progressive and cell nonautonomous increase in striatal neural stem cells in the Huntington's disease R6/2 mouse. J Neurosci 26:10452-10460.

Benraiss A, Chmielnicki E, Lerner K, Roh D, Gold- man SA (2001) Adenoviral brain-derived neurotrophic factor induces both neostriatal and olfactory neuronal recruitment from endogenous progenitor cells in the adult forebrain. J Neurosci 21:6718-6731

Curtis MA, Penney EB, Pearson AG, van RoonMom WM, Butterworth NJ, Dragunow M, Connor B, Faull RL (2003) Increased cell proliferation and neurogenesis in the adult human Huntington's disease brain. Proc Natl Acad Sci USA 100:9023-9027.

Curtis MA, Penney EB, Pearson J, Dragunow M, Connor B, Faull RL (2005) The distribution of progenitor cells in the subependymal layer of the lateral ventricle in the normal and Huntington's disease human brain. Neuroscience 132:777-788.

Gil JM, Mohapel P, Araujo IM, Popovic N, Li JY, Brundin P, Petersen A (2005) Reduced hippocampal neurogenesis in R6/2 transgenic Huntington's disease mice. Neurobiol Dis 20:744-751.

Lazic SE, Grote H, Armstrong RJ, Blakemore C, Hannan AJ, van Dellen A, Barker RA (2004) Decreased hippocampal cell proliferation in R6/1 Huntington's mice. NeuroReport 15:811-813.

Lazic SE, Grote HE, Blakemore C, Hannan AJ, van Dellen A, Phillips W, Barker RA (2006) Neurogenesis in the R6/1 transgenic mouse model of Huntington's disease: effects of environmental enrichment. Eur J Neurosci 23:1829-1838.

Phillips W, Morton AJ, Barker RA (2005) Abnormalities of neurogenesis in the R6/2 mouse model of Huntington's disease are attributable to the in vivo microenvironment. J Neurosci 25:11564-11576.

Phillips W, Morton AJ, Barker RA (2006) Limbic neurogenesis/plasticity in the R6/2 mouse model of Huntington's disease. NeuroReport 17:1623-1627.

Tattersfield AS, Croon RJ, Liu YW, Kells AP, Faull RL, Connor B (2004) Neurogenesis in the striatum of the quinolinic acid lesion model of Huntington's disease. Neuroscience 127:319-332.

Vazey EM, Chen K, Hughes SM, Connor B (2006) Transplanted adult neural progenitor cells survive, differentiate and reduce motor function impairment in a rodent model of Huntington's disease. Exp Neurol 199:384-396.

Zuccato C, Liber D, Ramos C, Tarditi A, Rigamonti D, Tartari M, Valenza M, Cattaneo E (2005) Progressive loss of BDNF in a mouse model of Huntington's disease and rescue by BDNF delivery. Pharmacol Res 52:133-139. 